\title{
Effect of tumor size on prognosis in patients with non- small cell lung cancer: The role of segmentectomy as a type of lesser resection
}

\author{
Morihito Okada, MD, PhD \\ Wataru Nishio, MD, PhD \\ Toshihiko Sakamoto, MD, PhD \\ Kazuya Uchino, MD \\ Tsuyoshi Yuki, MD \\ Akio Nakagawa, MD \\ Noriaki Tsubota, MD, PhD
}

From the Department of Thoracic Surgery,
Hyogo Medical Center for Adults, Hyogo, Japan.

Received for publication Feb 6, 2004; revisions received March 25, 2004; accepted for publication April 6, 2004.

Address for reprints: Morihito Okada, MD, $\mathrm{PhD}$, Hyogo Medical Center for Adults, Department of Thoracic Surgery, Kitaohjicho 13-70, Akashi City, Hyogo 673-8558, Japan (E-mail: morihito1217jp@aol.com).

J Thorac Cardiovasc Surg 2005;129:87-93

$0022-5223 / \$ 30.00$

Copyright $(9) 2005$ by The American Association for Thoracic Surgery

doi:10.1016/j.jtcvs.2004.04.030
Objective: As a result of increasing discovery of small-sized lung cancer in clinical practice, tumor size has come to be considered an important variable affecting planning of treatment. Nevertheless, there have been no reports including large numbers of patients and focusing on tumor size, and controversy remains concerning the surgical management of small-sized tumors. Therefore, we investigated the relationships between tumor dimension and clinical and follow-up data, as well as surgical procedure in particular.

Methods: We reviewed the records of 1272 consecutive patients who underwent complete resection for non-small cell carcinoma of the lung.

Results: Fifty patients had tumors of $10 \mathrm{~mm}$ or less, 273 had tumors of 11 to $20 \mathrm{~mm}$, $368 \mathrm{had}$ tumors of 21 to $30 \mathrm{~mm}$, and 581 had tumors of greater than $30 \mathrm{~mm}$ in diameter. The cancer-specific 5-year survivals of patients in these 4 groups were $100 \%, 83.5 \%, 76.5 \%$, and $57.9 \%$, respectively. For patients with pathologic stage I disease, they were $100 \%, 92.6 \%, 84.1 \%$, and $76.4 \%$, respectively. Multivariate analysis demonstrated that male sex, older age, larger tumor, and advanced pathologic stage adversely affected survival. Lesser resection was performed in 167 (52\%) of 323 patients with a tumor of $20 \mathrm{~mm}$ or less in diameter but in $156(16 \%)$ of 949 patients with a tumor of greater than $20 \mathrm{~mm}$ in diameter. The percentages of lesser resection among all procedures performed were $79 \%, 56 \%, 30 \%$, and $15 \%$ in patients with pathologic stage I disease with a tumor of $10 \mathrm{~mm}$ or less, 11 to $20 \mathrm{~mm}$, 21 to $30 \mathrm{~mm}$, and greater than $30 \mathrm{~mm}$ in diameter, respectively. The 5-year cancer-specific survivals of patients with pathologic stage I disease with tumors of $20 \mathrm{~mm}$ or less and 21 to $30 \mathrm{~mm}$ in diameter were $92.4 \%$ and $87.4 \%$ after lobectomy, $96.7 \%$ and $84.6 \%$ after segmentectomy, and $85.7 \%$ and $39.4 \%$ after wedge resection, respectively. On the other hand, with a tumor of greater than $30 \mathrm{~mm}$ in diameter, survivals were $81.3 \%$ after lobectomy, $62.9 \%$ after segmentectomy, and $0 \%$ after wedge resection, respectively.

Conclusions: Tumor size is an independent and significant prognostic factor and important for planning of surgical treatment. Although lobectomy should be chosen for patients with a tumor of greater than $30 \mathrm{~mm}$ in diameter, further investigation is required for tumors of 21 to $30 \mathrm{~mm}$ in diameter. Segmentectomy should, as a lesser anatomic resection, be distinguished from wedge resection and might be acceptable for patients with a tumor of $20 \mathrm{~mm}$ or less in diameter without nodal involvement. 


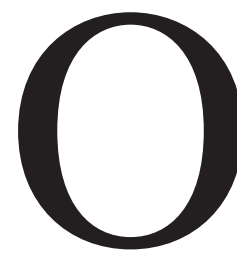

$\mathrm{f}$ late, as a consequence of advances in diagnostic imaging, such as high-resolution or spiral computed tomography and positron emission tomographic scanning, thoracic surgeons have encountered small-sized lung cancers at an earlier and potentially curable stage. It has thus become increasingly crucial to examine how clinical and oncologic behaviors are related to tumor dimension and thereby to choose the most advantageous treatment strategy, including surgical intervention. Although the traditional TNM staging system exists, ${ }^{1}$ it might become obsolete within a few years and should be revised with new findings. As stated by the TNM system, the boundary of $\mathrm{T}$ status is a tumor $3 \mathrm{~cm}$ in diameter. Recent studies have, however, demonstrated that the postoperative prognosis of patients with non-small cell lung cancer of $2 \mathrm{~cm}$ or less in diameter is significantly better than that of patients with a larger tumor. ${ }^{2-5}$ Controversy also exists regarding the extent of lung removal necessary for cure, especially for small-sized cancers. Although lobectomy or pneumonectomy has traditionally been considered the standard of care for resectable disease, the significance of lesser resection in the treatment of early non-small cell cancer has attracted increased interest as a minimally invasive operation with the advancement of video-assisted thoracic surgery. Arguments favoring the less-invasive operation include potential preservation of pulmonary function, lower morbidity-mortality, and shorter hospitalization. Surprisingly, there are no reports of large numbers of patients focusing on tumor dimension, one of the most subjective reoperative variables. Thus, newer information for selection of surgical intervention on the basis of tumor size is required.

We evaluated the role of tumor size, which has had increased clinical importance because of the increasing discovery of small-sized lung cancer in clinical practice. The aims of this study were to compare the clinical characteristics and follow-up data of patients subjected to complete resection of non-small cell lung cancer with tumor dimension, with special reference to determination of the appropriate surgical mode of treatment.

\section{Patients and Methods}

Between January 1985 and December 2002, a series of 1272 consecutive patients operated on for primary non-small cell carcinoma of the lung were pathologically confirmed to have complete removal with systematic nodal dissection of the hilum and mediastinum. Institutional review board approval was obtained for collection of their data in a secure database and reporting of analyses of that data. The histologic type of the tumor was determined by the World Health Organization classification. Patients with low-grade malignancy of the lung, such as carcinoid, were excluded. Staging was determined according to the international TNM staging system. Patients who had been subjected to preoperative chemotherapy or radiotherapy were excluded.

The maximum dimension of a tumor was measured using resected primary lesion specimens. Generally, the patients were postoperatively examined at 3-month intervals for 5 years and thereafter at 1-year intervals to check for recurrence and survival. We used physical and biochemical examination, chest radiography, computed tomography of the chest, brain, and upper portion of the abdomen, and bone scintigraphy for evaluation of recurrence.

Survivals were calculated by the Kaplan-Meier method, and differences in survival were determined by log-rank analysis. A multivariate analysis for prognostic factors was carried out by the Cox proportional hazards regression model. We analyzed the prognosis of patients in two fashions, to determine overall and cancer-related survivals. Zero time was the date of pulmonary resection, and the terminal event was death attributable to cancer-related survival, although the terminal point for overall survival was any death due to cancer, noncancerous, or unknown causes.

\section{Results}

Patients were divided into 4 groups for comparison by size of resected tumor. Fifty patients had a primary tumor with a diameter of $10 \mathrm{~mm}$ or less, 273 patients had a tumor of 11 to $20 \mathrm{~mm}, 368$ patients had a tumor of 21 to $30 \mathrm{~mm}$, and 581 patients had a tumor of greater than $30 \mathrm{~mm}$ in diameter. Clinical characteristics, pathologic stage, and surgical mode are summarized in Table 1, which shows that larger lesions had high degrees of association with old age, male sex, squamous cell carcinoma, and advanced-stage disease. Notably, half of the patients with a subcentimeter tumor were female, $70 \%$ of the patients had adenocarcinoma, and 96\% had pathologic stage IA disease, although $4 \%$ had stage III disease. Larger resections were, as a general rule, selected for larger lesions. On the other hand, lesser resections, such as segmentectomy, were preferred for smaller lesions without proof of nodal involvement, as determined by intraoperative pathologic examination. As a result, lesser resections were performed in $167(52 \%)$ of 323 patients with a tumor of $20 \mathrm{~mm}$ or less in diameter and in $156(16 \%)$ of 949 patients with a tumor of greater than $20 \mathrm{~mm}$ in diameter. Of 50 patients with subcentimeter cancer, 38 (76\%) underwent lesser resection, including 27 (54\%) with segmentectomy. There were $3(3 / 1272$ [0.2\%]) operative deaths. Causes of death were acute pancreatitis and bleeding during reoperation. The third patient died suddenly at home on the 30th postoperative day as a result of myocardial infarction. Follow-up was almost complete and ranged from 12 to 225 months, with a median of 61 months for surviving patients. The overall 5-year survivals of patients with a tumor of 10 $\mathrm{mm}$ or less, 11 to $20 \mathrm{~mm}, 21$ to $30 \mathrm{~mm}$, and greater than 30 
TABLE 1. Characteristics of patients with complete resection for non-small cell lung cancer, pathologic findings, and surgical interventions according to tumor size

\begin{tabular}{|c|c|c|c|c|c|}
\hline & \multicolumn{2}{|c|}{ Tumor size (mm) } & \multirow[b]{2}{*}{$\begin{array}{c}21-30 \\
\text { (n }=368)\end{array}$} & \multirow[b]{2}{*}{$\begin{aligned} & \geq 31 \\
&(n=581)\end{aligned}$} & \multirow[b]{2}{*}{$\begin{array}{c}\text { Total } \\
\text { (n }=1272)\end{array}$} \\
\hline & $\begin{array}{c}\leq 10 \\
(n=50)\end{array}$ & $\begin{array}{c}11-20 \\
(n=273)\end{array}$ & & & \\
\hline Age (y) & $62(40-79)$ & $64(38-85)$ & $65(36-85)$ & $65(30-85)$ & $65(30-88)$ \\
\hline \multicolumn{6}{|l|}{ Sex } \\
\hline Male & $25(50 \%)$ & $170(62 \%)$ & $249(68 \%)$ & $455(78 \%)$ & $899(71 \%)$ \\
\hline Female & $209(77 \%)$ & $254(69 \%)$ & $284(49 \%)$ & $782(61 \%)$ & \\
\hline Average size (mm) & 7.5 & 16.7 & 25.8 & 47.6 & 33.1 \\
\hline \multicolumn{6}{|l|}{ Histology } \\
\hline$A D$ & $35(70 \%)$ & $209(77 \%)$ & $254(69 \%)$ & $284(49 \%)$ & $782(61 \%)$ \\
\hline SO & $15(30 \%)$ & $61(22 \%)$ & $105(29 \%)$ & $275(47 \%)$ & $456(36 \%)$ \\
\hline LA & 0 & $3(1 \%)$ & $9(2 \%)$ & $2(0.3 \%)$ & $34(3 \%)$ \\
\hline \multicolumn{6}{|l|}{ Pathologic stage } \\
\hline IA & $48(96 \%)$ & $208(76 \%)$ & $233(63 \%)$ & 0 & $489(38 \%)$ \\
\hline IB & 0 & $9(3 \%)$ & $2(1 \%)$ & $258(44 \%)$ & $289(23 \%)$ \\
\hline$\| \mathrm{A}$ & 0 & $21(8 \%)$ & $42(11 \%)$ & 0 & $63(5 \%)$ \\
\hline IIB & 0 & $5(2 \%)$ & $18(5 \%)$ & $141(24 \%)$ & $164(13 \%)$ \\
\hline IIIA & $1(2 \%)$ & $23(8 \%)$ & $39(11 \%)$ & $129(22 \%)$ & $192(15 \%)$ \\
\hline IIIB & $1(2 \%)$ & $7(3 \%)$ & $14(4 \%)$ & $53(9 \%)$ & $75(6 \%)$ \\
\hline \multicolumn{6}{|l|}{ Procedure } \\
\hline PN & 0 & $2(1 \%)$ & $5(1 \%)$ & $23(4 \%)$ & $30(2 \%)$ \\
\hline LO & $12(24 \%)$ & $142(52 \%)$ & $268(73 \%)$ & $497(86 \%)$ & $919(72 \%)$ \\
\hline SE & $27(54 \%)$ & $102(37 \%)$ & $76(21 \%)$ & $53(9 \%)$ & $258(20 \%)$ \\
\hline WE & $10(20 \%)$ & $27(10 \%)$ & $19(5 \%)$ & $8(1 \%)$ & $64(5 \%)$ \\
\hline $\mathrm{BR}$ & $1(2 \%)$ & 0 & 0 & 0 & $1(0.1 \%)$ \\
\hline
\end{tabular}

$A D$, Adenocarcinoma; $S Q$, squamous cell carcinoma; $L A$, large cell carcinoma; $P N$, pneumonectomy; $L O$, lobectomy; $S E$, segmentectomy; $W E$, wedge resection; $B R$, bronchial resection.

TABLE 2. Multivariate analyses for overall and cancer-specific prognosis in patients with complete resection for non-small cell lung cancer

\begin{tabular}{|c|c|c|c|c|c|}
\hline Factors & Unfavorable & Favorable & Risk ratio & $95 \% \mathrm{CI}$ & $P$ value \\
\hline \multicolumn{6}{|c|}{ Prognosis for overall deaths } \\
\hline Sex & Male & Female & 1.772 & $1.397-2.247$ & $<.0001$ \\
\hline Age & Older & Younger & 1.030 & $1.019-1.042$ & $<.0001$ \\
\hline Size & Larger & Smaller & 1.003 & $1.001-1.005$ & .0035 \\
\hline Histology & Non-AD & $A D$ & 1.059 & $0.874-1.284$ & .5587 \\
\hline P-stage & Advanced & Early & 2.027 & $1.821-2.257$ & $<.0001$ \\
\hline Procedure & $\mathrm{PN}+\mathrm{LO}$ & $\mathrm{SE}+\mathrm{WE}+\mathrm{BR}$ & 1.049 & $0.818-1.345$ & .7039 \\
\hline \multicolumn{6}{|c|}{ Prognosis for cancer-specific deaths } \\
\hline Sex & Male & Female & 1.569 & $1.184-2.078$ & .0017 \\
\hline Age & Older & Younger & 1.014 & $1.001-1.027$ & .0387 \\
\hline Size & Larger & Smaller & 1.004 & $1.002-1.006$ & $<.0001$ \\
\hline Histology & Non-AD & $A D$ & 1.136 & $0.894-1.443$ & .2969 \\
\hline P-stage & Advanced & Early & 2.430 & $2.129-2.773$ & $<.0001$ \\
\hline Procedure & PN+LO & $\mathrm{SE}+\mathrm{WE}+\mathrm{BR}$ & 1.047 & $0.761-1.442$ & .7763 \\
\hline
\end{tabular}

$C I$, Confidence interval; $A D$, adenocarcinoma; $P N$, pneumonectomy; $L O$, lobectomy; $S E$, segmentectomy; $W E$, wedge resection; $B R$, bronchial resection. Continuous variables for age, size, and p-stage, and categories for gender, histology and procedures are given.

$\mathrm{mm}$ in diameter were $87.3 \%, 75.5 \%, 68.0 \%$, and $49.0 \%$, respectively (Figure 1, $A$ ), whereas the corresponding cancer-specific 5-year survivals were $100 \%, 83.5 \%, 76.5 \%$, and $57.9 \%$, respectively (Figure 1, B). There were significant differences in survivals among the 4 groups. Additionally, for patients with pathologic stage I disease, the overall 5 -year survivals of the 4 groups noted above were $86.0 \%$, $83.8 \%, 75.3 \%$, and $67.0 \%$, respectively (Figure 2, A), 


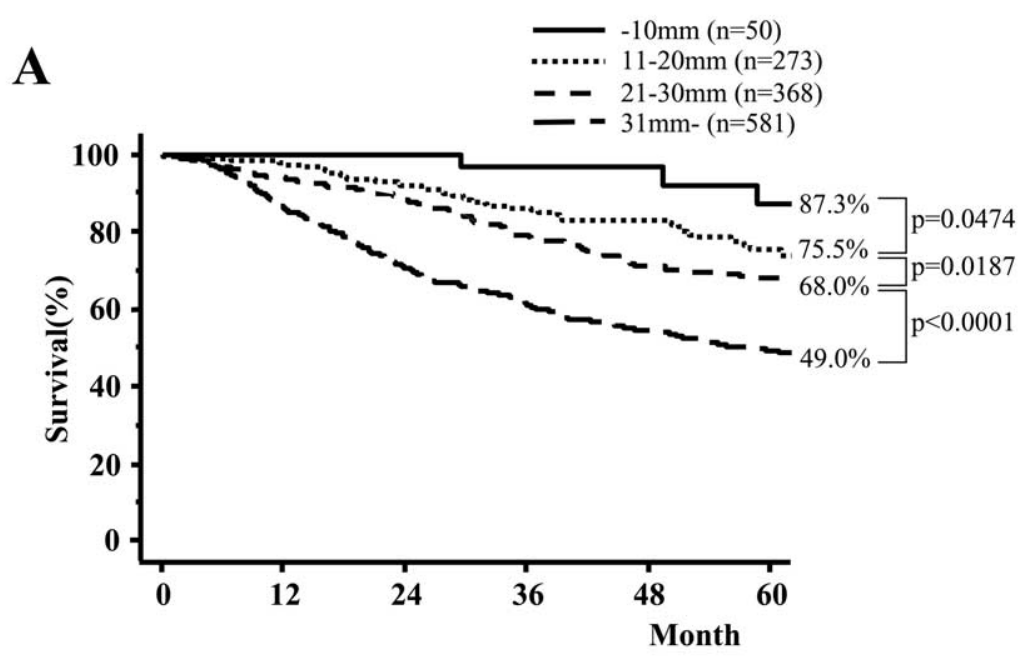

B

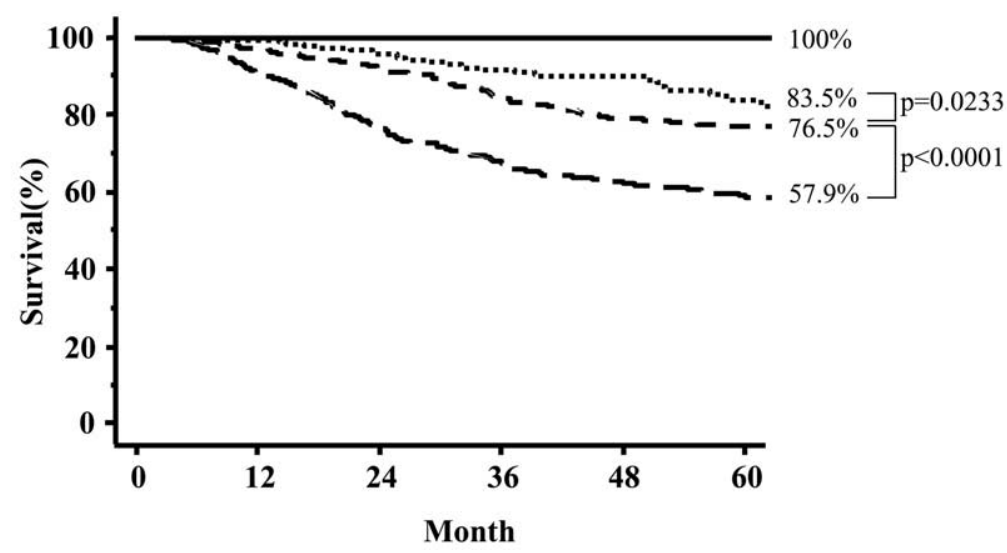

Figure 1. Overall (A) and cancer-specific (B) survival curves for patients with complete resection for non-small cell lung cancer according to tumor size.

whereas their cancer-specific 5-year survivals were 100\%, $92.6 \%, 84.1 \%$, and $76.4 \%$, respectively (Figure $2, B$ ). There were significant differences in these survivals between patients with a tumor of 11 to $20 \mathrm{~mm}$ in diameter and those with a tumor of 21 to $30 \mathrm{~mm}$ in diameter.

Univariate analyses demonstrated that male sex $(P<$ $.0001)$, age older than 65 years $(P=.0003)$, tumor size larger than $30 \mathrm{~mm}(P<.0001)$, nonadenocarcinoma $(P=$ $.0004)$, advanced pathologic stage $(P<.0001)$, and formal resections, including lobectomy and pneumonectomy $(P=$ .0014), significantly and negatively affected overall survival. Next we performed multivariate analyses for prognosis by using these key variables (Table 2) and found that male sex, older age, larger tumor, and advanced pathologic stage adversely affected overall and cancer-specific survivals, whereas neither histology nor surgical procedure sig- nificantly influenced survival on stratification by other variables.

We examined the relationships between surgical mode and tumor size and their association with postoperative survival. The percentages of lesser resection among all procedures completed were $79 \%$ (38/48), 56\% (121/217), $30 \%(78 / 255)$, and $15 \%(40 / 258)$ in patients with stage I disease with a tumor of $10 \mathrm{~mm}$ or less, 11 to $20 \mathrm{~mm}, 21$ to $30 \mathrm{~mm}$, and greater than $30 \mathrm{~mm}$ in diameter, respectively. Although only patients without nodal involvement were included in these survival analyses, there were no cancerspecific deaths in patients with a tumor of $10 \mathrm{~mm}$ or less in diameter, irrespective of surgical mode. The 5-year cancerspecific survivals of patients with stage I disease with a tumor of $20 \mathrm{~mm}$ or less in diameter were $96.7 \%$ after segmentectomy, $92.4 \%$ after lobectomy, and $85.7 \%$ after 


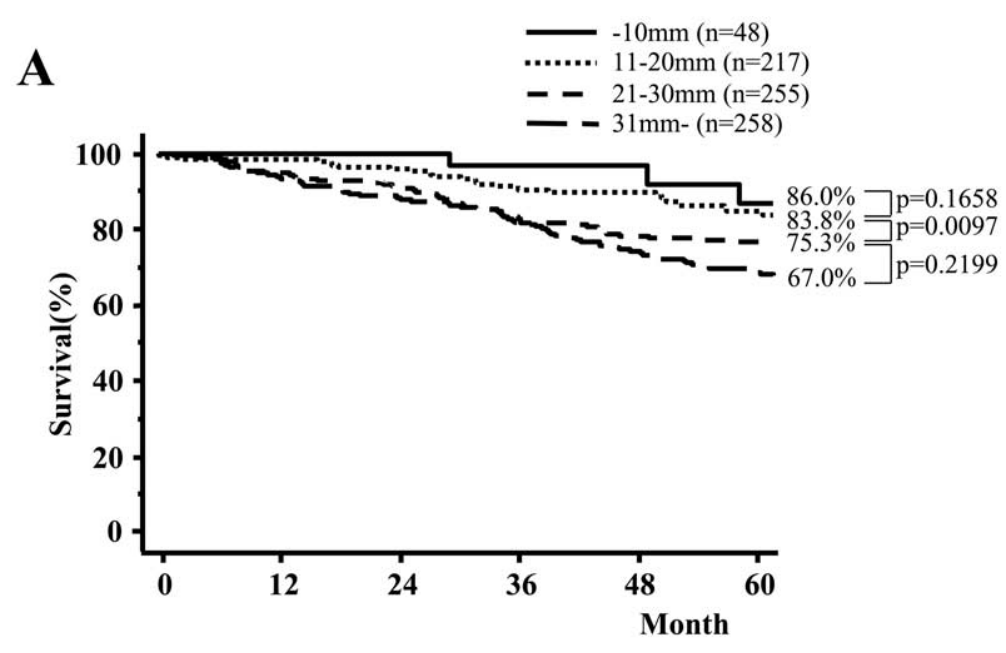

B

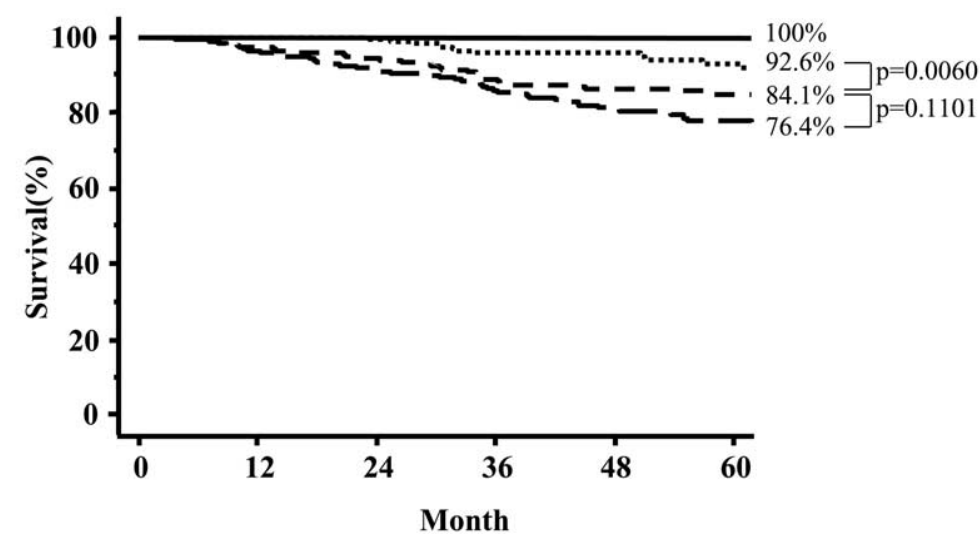

Figure 2. Overall (A) and cancer-specific (B) survival curves for patients with complete resection for pathologic stage I non-small cell lung cancer according to tumor size.

wedge resection (Figure 3,A). There were no significant differences between these procedures. In addition, the 5 -year cancer-specific survivals of patients with stage I disease with a tumor of 21 to $30 \mathrm{~mm}$ in diameter were $87.4 \%$ after lobectomy, $84.6 \%$ after segmentectomy, and $39.4 \%$ after wedge resection (Figure 3, B). There were significant differences between wedge resection and the other modes but not between lobectomy and segmentectomy. In patients with stage I disease with a tumor of greater than $30 \mathrm{~mm}$ in diameter, the 5-year cancer-specific survivals were $81.3 \%$ after lobectomy, $62.9 \%$ after segmentectomy, and $0 \%$ after wedge resection (Figure 3,C). There were significant differences between all matchings.

\section{Discussion}

Tumor dimension was clearly shown to be a significant predictor of survival not only by univariate analysis but also by multivariate analysis. In the present international TNM staging system, the cutoff value of $\mathrm{T}$ factor (tumor size) is $30 \mathrm{~mm},{ }^{1}$ which is a contentious problem. In addition to reports that patients with a tumor of $2 \mathrm{~cm}$ or less in diameter had a better survival than those with a tumor of 2.1 to $3.0 \mathrm{~cm}$ in diameter, ${ }^{4,6}$ we demonstrated that patients with a tumor of 11 to $20 \mathrm{~mm}$ in diameter had significantly better overall and cancer-specific survivals than those with a tumor of 21 to $30 \mathrm{~mm}$ in diameter among patients with completely resected pathologic stage I tumors excluding lymph node involvement, but there were no significant differences in overall or cancer-specific survivals between patients with a tumor of 21 to $30 \mathrm{~mm}$ in diameter and those with a tumor of larger than $30 \mathrm{~mm}$ in diameter. These findings suggest that $20 \mathrm{~mm}$ is preferable as a cutoff value for $\mathrm{T}$ factor in staging.

Tumor size was not the only factor that affected prognosis after complete resection. Additionally, sex, age, histologic type, pathologic stage, and operative procedure significantly affected survival on univariate tests. Surprisingly, 

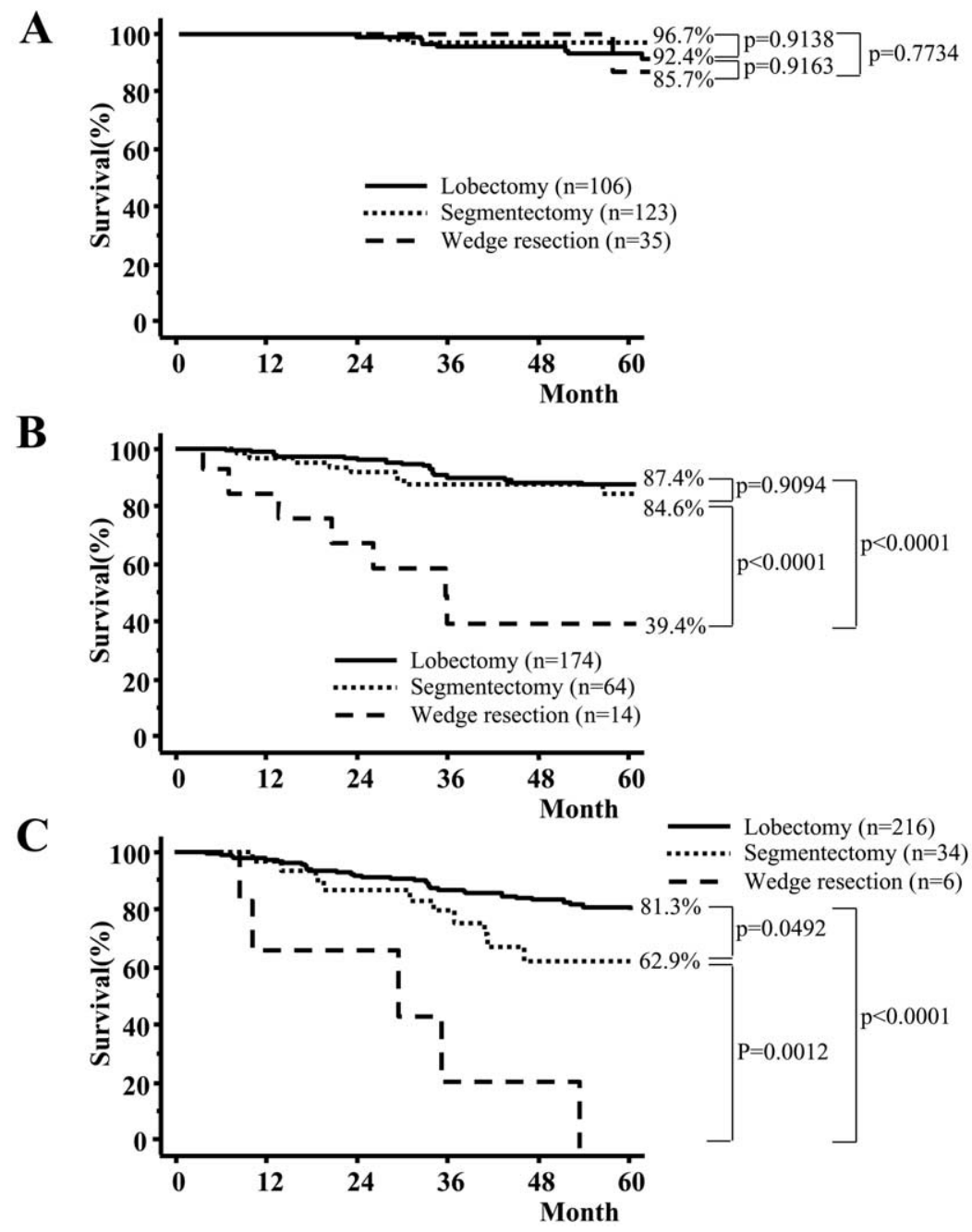

Figure 3. Cancer-specific survival curves for patients with complete resection for pathologic stage I non-small cell lung cancer of $20 \mathrm{~mm}$ or less (A), 21 to $30 \mathrm{~mm}$ (B), and greater than $30 \mathrm{~mm}$ in diameter according to operative procedure.

the prognosis after formal surgical intervention, which included lobectomy and pneumonectomy, was worse than that after lesser operations, probably because we tended to remove less lung parenchyma for earlier-stage cancers. To certify this hypothesis, we evaluated the relationships between operative procedure and survival on multivariate tests, which were unable to correlate the 2 factors. A total of $4 \%$ of our patients were found to have any advanced factor, even though tumors measured $10 \mathrm{~mm}$ or less in diameter. In our series, tumors of 11 to $20 \mathrm{~mm}$ and 21 to $30 \mathrm{~mm}$ in diameter had $21 \%$ and $36 \%$ advanced factors, respectively, whereas $56 \%$ of tumors greater than $30 \mathrm{~mm}$ in diameter were associated with higher-stage disease. Others have obtained similar results. ${ }^{3,7}$ Supporters of lesser resection in noncompromised patients maintain that even for small-sized tumors there is minimal risk of advanced disease, such as nodal involvement, and that it might be essential to identify risks preoperatively or intraoperatively. The proportions of lesser resection in the total procedures were $74 \%$ (37/50), $47 \%(129 / 273)$, and $26 \%$ (95/368) for patients with a tumor of $10 \mathrm{~mm}$ or less, 11 to $20 \mathrm{~mm}$, and 21 to $30 \mathrm{~mm}$ in diameter, respectively; when limited to patients with stage I disease, they were 79\% (38/48), 56\% (121/217), and 30\% (78/255), respectively. We have always maintained the policy that removal of lung parenchyma should deliberately be reduced as long as oncologic radicality can be preserved. In this study we analyzed follow-up data in terms of overall survival and cancer-specific survival and believe the latter is probably more appropriate for examination of results. If there is essentially no statistically significant difference in cancer-specific survival between lobectomy and lesser resection, and the 5-year survivals with the 2 types of proce- 
dures are equal, on what basis can one conclude that lobectomy is better?

Since 1992, at our institute we have, as a prospective trial, tried segmentectomy with lymph node dissection in noncompromised patients with stage IA non-small cell lung cancer of $2 \mathrm{~cm}$ or smaller in diameter who had undergone lobectomy up to that time. ${ }^{2,8,9}$ Continuing controversy exists concerning the role of segmentectomy but not that of wedge resection in noncompromised patients with primary lung cancer, although it is not debated for benign diseases, metastatic tumors, or selected primary cancers in compromised patients. In 1995, lobectomy had been confirmed to be a standard procedure of choice for tumors of any size. ${ }^{10}$ However, several sequential studies, including prospective ones, have shown the usefulness of segmentectomy for small-sized N0 cancer., ${ }^{2,8,9,11-13}$ Thus, current persuasive data suggest that for smaller N0 cancers, segmentectomy might be an acceptable surgical method, even in noncompromised patients.

In our series the frequency of segmentectomy was 5 times that of wedge resection. It was impossible to overemphasize the percentages of segmentectomy in all lesser resections. Because segmentectomy and wedge resection have thus far been combined and categorized together as types of lesser resection, we cannot evaluate the 2 procedures separately on the basis of results in the literature. We believe that segmentectomy is an anatomic procedure in which lymph nodes can be examined at various levels of N1. Some reports, as well as our own experience, have shown nonanatomic wedge resection to be inferior to anatomic segmentectomy. ${ }^{12,14}$ Segmentectomy should be carefully distinguished from wedge resection in practice and clinical research, as in this study. Recently, few segmentectomies are being performed and many thoracic surgeons are not familiar with this useful method. ${ }^{15}$ Although technically more challenging than other resections, segmentectomy is valuable and should be kept in mind by younger thoracic surgeons.

\section{References}

1. Mountain CF. Revisions in the International System for Staging Lung Cancer. Chest. 1997;111:1710-7.

2. Okada M, Yoshikawa K, Hatta T, Tsubota N. Is segmentectomy with lymph node assessment an alternative to lobectomy for non-small cell lung cancer of $2 \mathrm{~cm}$ or smaller? Ann Thorac Surg. 2001;71:956-60.

3. Koike T, Terashima M, Takizawa $\mathrm{T}$, Watanabe $\mathrm{T}$, Kurita $\mathrm{Y}$, Yokoyama A. Clinical analysis of small-sized peripheral lung cancer. J Thorac Cardiovasc Surg. 1998;115:1015-20.

4. Read RC, Yoder G, Schaeffer RC. Survival after conservative resection for T1 N0 M0 non-small cell lung cancer. Ann Thorac Surg. 1990;49:391-8.

5. Okada M, Sakamoto T, Nishio W, Uchino K, Tsubota N. Characteristics and prognosis of patients after resection of nonsmall cell lung carcinoma measuring $2 \mathrm{~cm}$ or less in greatest dimension. Cancer. 2003;98:535-41.

6. Warren WH, Faber LP. Segmentectomy versus lobectomy in patients with stage I pulmonary carcinoma: five-year survival and patterns of intrathoracic recurrence. J Thorac Cardiovasc Surg. 1994;107:1087-93.

7. Ishida T, Yano T, Maeda K, Kaneko S, Tateishi M, Sugimachi K. Strategy for lymphadenectomy in lung cancer three centimeters or less in diameter. Ann Thorac Surg. 1990;50:708-13.

8. Tsubota N, Ayabe K, Doi O, Mori T, Namikawa S, Taki T, et al. Ongoing prospective study of segmentectomy for small lung tumors. Study Group of Extended Segmentectomy for Small Lung Tumor. Ann Thorac Surg. 1998;66:1787-90.

9. Yoshikawa K, Tsubota N, Kodama K, Ayabe H, Taki T, Mori T. Prospective study of extended segmentectomy for small lung tumors: the final report. Ann Thorac Surg. 2002;73:1055-8.

10. Ginsberg RJ, Rubinstein LV. Randomized trial of lobectomy versus limited resection for T1 N0 non-small cell lung cancer. Lung Cancer Study Group. Ann Thorac Surg. 1995;60:615-22.

11. Kodama K, Doi O, Higashiyama M, Yokouchi H. Intentional limited resection for selected patients with T1 N0 M0 non-small-cell lung cancer: a single-institution study. J Thorac Cardiovasc Surg. 1997;114: 347-53.

12. Miller DL, Rowland CM, Deschamps C, Allen MS, Trastek VF, Pairolero PC. Surgical treatment of non-small cell lung cancer $1 \mathrm{~cm}$ or less in diameter. Ann Thorac Surg. 2002;73:1545-50.

13. Sagawa M, Koike T, Sato M, Oda M, Kondo T, Kato H, et al. Segmentectomy for roentgenographically occult bronchogenic squamous cell carcinoma. Ann Thorac Surg. 2001;71:1100-14.

14. Cerfolio RJ, Allen MS, Trastek VF, Deschamps C, Scanlon PD, Pairolero PC. Lung resection in patients with compromised pulmonary function. Ann Thorac Surg. 1996;62:348-51.

15. Jones DR, Stiles BM, Denlinger CE, Antippa P, Daniel TM. Pulmonary segmentectomy: results and complications. Ann Thorac Surg. 2003;76:343-8. 